\title{
Pengaruh ekstrak udang pada umpan terhadap hasil tangkapan pancing dasar di perairan Tateli Weru, Kabupaten Minahasa
}

\author{
The effect of shrimp extract oil added to the bait on catches of bottom hand line in Tateli Weru \\ waters, Minahasa
}

\author{
UCHA E. JANIS*, ALFRET LUASUNAUNG dan LEFRAND MANOPPO \\ Program Studi Pemanfaatan Sumberdaya Perikanan, Fakultas Perikanan dan Ilmu Kelautan, \\ Universitas Sam Ratulangi, Manado 95115
}

\begin{abstract}
The success of baited hook and line fishing gear is determined by the activity of fish in terms of finding and catching food. Adding shrimp extract on bait may increase the fishing power of the bait; but this kind of scientific information, particularly on the bottom hand line is not widely available. This study aimed to determine the effect of shrimp extracts on demersal fish catch in the surrounding fishing ground and to identify the species caught by the bottom hand line. This research was conducted in coastal waters Tateli Weru Village, District of Mandolang, Minahasa in October 2015 which was based on an experimental method. Six units of bottom hand line was operated, where three units using bait of scad mackerel marinated in shrimp extract, and three other units using plain bait of scad mackerel; and the data were analyzed using t-test. Total catches was 60 fish; 38 fish caught by bait with shrimp extract, and 22 fish caught by bait without shrimp extract. The results showed that use of bait with shrimp extract give more catches.
\end{abstract}

Keywords: bottom hand line, extrack of shrimp, demersal fish, Tateli Weru

\begin{abstract}
ABSTRAK
Keberhasilan alat tangkap pancing dasar berumpan sangat ditentukan oleh aktivitas hidup ikan dalam hal mencari dan menangkap makanan. Pemberian ekstrak udang pada umpan diduga dapat meningkatkan kemampuan tangkap dari umpan; namun informasi ilmiah seperti ini, khususnya pada pancing dasar belum banyak tersedia. Penelitian ini bertujuan untuk mengetahui pengaruh ekstrak udang terhadap hasil tangkapan ikan demersal di sekitar daerah penangkapan dan mengidentifikasi jenis ikan hasil tangkapan pancing dasar. Penelitian ini dilakukan di perairan pantai Desa Tateli Weru, Kecamatan Mandolang Kabupaten Minahasa pada bulan Oktober 2015 yang didasarkan pada metode experimental. Enam unit pancing dasar dioperasikan, di mana tiga unit menggunakan umpan ikan malalugis yang direndam dalam ekstrak udang, dan tiga unit lainnya hanya menggunakan umpan ikan malalugis tanpa ekstrak; dan data dinalisis dengan uji t. Tangkapan total berjumlah 60 ekor; 38 ekor tertangkap dengan umpan yang diberi ekstrak udang, dan 22 ekor tertangkap dengan umpan tidak memiliki ekstrak udang. Hasil analisis menunjukkan bahwa penggunaan ekstrak udang pada umpan memberikan hasil tangkapan yang lebih banyak.
\end{abstract}

Kata-kata kunci: pancing dasar, ekstrak udang, ikan demersal, Tateli Weru

\section{PENDAHULUAN}

Pancing dasar (bottom hand line) merupakan salah satu alat tangkap yang umum digunakan oleh masyarakat nelayan untuk menangkap ikan-ikan karang, karena konstruksinya sederhana, relatif murah dan mudah dioperasikan dengan kapal atau perahu ukuran kecil. Walaupun alat tangkap ini

\footnotetext{
*Penulis untuk penyuratan; email: uchajanis@gmail.com
}

telah berkembang sejak lama, tetapi efisiensi penangkapan ikan dan selektivitasnya masih memiliki potensi pengembangan untuk memenuhi kriteria ramah lingkungan dan berkelanjutan.

Keberhasilan alat tangkap pancing dasar berumpan sangat ditentukan oleh aktivitas hidup ikan dalam hal mencari dan menangkap makanan. Pengetahuan yang diperoleh melalui studi-studi tentang tingkah laku ikan mengambil makanan 
akan sangat membantu untuk memahami interaksi spesies target dengan alat tangkap berumpan (Lokkeborg, 1994). Umpan merupakan salah satu faktor penting dalam menunjang keberhasilan suatu operasi penangkapan ikan, khususnya untuk alat tangkap pasif seperti bubu dan pancing (Subani dan Barus, 1989). Pemberian ekstrak udang pada umpan diduga dapat meningkatkan kemampuan tangkap dari pancing dasar, namun informasi ilmiah hal ini belum banyak tersedia.

Kawasan perairan desa Tateli Weru, Kabupaten Minahasa merupakan salah satu kawasan perairan yang telah dimanfaatkan untuk kegiatan perikanan tangkap. Penelitian ini bertujuan untuk mengetahui pengaruh ekstrak udang terhadap hasil tangkapan ikan demersal di sekitar daerah penangkapan dan mengidentifikasi jenis-jenis ikan hasil tangkapan pancing dasar.

\section{METODE PENELITIAN}

Penelitian ini dilakukan di perairan pantai Desa Tateli Weru, Kecamatan Mandolang, Kabupaten Minahasa pada bulan Oktober 2015. Penelitian ini dikerjakan dengan mengikuti metode eksperimental, yaitu suatu rancangan percobaan yang diujicobakan untuk memperoleh informasi tentang persoalan yang sedang diteliti. Dengan metode ini dapat diperoleh informasi yang diperlukan dalam melakukan penelitian tentang persoalan yang akan dibahas sehingga akan dihasilkan suatu kesimpulan sesuai dengan tujuan penelitian (Sudjana, 1994).

Bahan dan alat yang digunakan dalam penelitian terdiri dari umpan alami yaitu ikan layang, ekstrak udang, alat tangkap pancing dasar (6 unit), perahu tipe pelang ( 2 unit), mistar, alat tulis menulis, GPS, kamera digital, jam tangan, cool box, dan pisau. Kedalaman perairan daerah operasi penangkapan sekitar 30-50 m. Pengoperasian alat tangkap pancing dasar dilakukan pada pagi hingga sore hari (06.00-17.00). Hasil tangkapan pancing dasar pada setiap jam operasi diidentifikasi, diukur dan dicatat berdasarkan pada masing-masing perlakuan.
Untuk memenuhi persyaratan analisis dalam menarik kesimpulan, maka dirumuskan hipotesis sebagai berikut:

$\mathrm{H}_{0}=$ Penggunaan umpan ekstrak udang tidak berbeda nyata terhadap hasil tangkapan

$\mathrm{H}_{1}=$ Penggunaan umpan ekstrak berbeda nyata, di mana, $\mathrm{H}_{0}$ diterima $\left(\mathrm{H}_{1}\right.$ ditolak) apabila $\mathrm{t}$ hitung $\leq \mathrm{t}$ tabel, $\mathrm{H}_{0}$ ditolak $\left(\mathrm{H}_{1}\right.$ diterima) apabila $\mathrm{t}$ hitung $>\mathrm{t}$ tabel. Selanjutnya nilai $\mathrm{t}$ dihitung dengan menggunakan analisis komparatif dua sampel berkorelasi (Soepeno, 2002), dengan rumus sebagai berikut:

$$
T=\frac{X-Y}{\sqrt{\frac{\sum \mathrm{D}^{2}-\frac{\left(\sum D\right)^{2}}{\mathrm{n}}}{\mathrm{n}-1}}}
$$

$T=\mathrm{t}$ hitung, $X=X$ rata-rata (umpan alami), $Y=Y$ rata-rata (umpan berekstrak), $D=$ beda skor pertama dan kuadrat beda skor, $n=$ jumlah hasil.

\section{HASIL DAN PEMBAHASAN}

\section{Hasil tangkapan}

Hasil tangkapan pancing dasar selama penelitian berjumlah 60 ekor, sebanyak 38 ekor tertangkap dengan umpan yang diberi ekstrak udang dan 22 ekor tertangkap dengan umpan tanpa ekstrak udang. Sebaran hasil tangkapan pancing dasar pada setiap trip dan ulangan disajikan dalam Tabel 1 dan 2.

\section{Hasil analisis}

Untuk analisis uji t, maka data disajikan ke dalam Tabel 3. Hasil analisis menunjukkan bahwa $\mathrm{t}$ hitung $=3,266>\mathrm{T}_{0,05 ; 5 \mathrm{n}}=2,571$; sehingga menolak $\mathrm{H}_{0}$ dan menerima $\mathrm{H}_{1}$, di mana hal ini menjelaskan bahwa penggunaan larutan ekstrak udang pada umpan pancing dasar, memberikan hasil tangkapan yang berbeda dengan umpan pancing dasar tanpa ekstrak udang. 
U.E. Janis dkk.

Tabel 1. Sebaran hasil tangkapan (ekor per jenis) dengan umpan berekstrak

\begin{tabular}{|c|c|c|c|c|c|c|c|c|c|c|c|c|c|c|c|c|c|}
\hline \multirow{2}{*}{ No } & \multirow{2}{*}{ Trip } & \multicolumn{16}{|c|}{ Jenis ikan } \\
\hline & & Bom & Tol & Mam & Gom & Cip & Gos & Tat & Seb & Bok & Bij & Luk & Gor & Gett & Gut & Pep & $T$ \\
\hline 1 & $\begin{array}{l}06.00- \\
07.00\end{array}$ & 3 & & 2 & 1 & & & 1 & & & 1 & & 1 & & & & 9 \\
\hline 2 & $\begin{array}{l}07.00- \\
08.00\end{array}$ & 1 & 1 & & & 1 & 2 & & & 1 & & & & 1 & & & 7 \\
\hline 3 & $\begin{array}{l}08.00- \\
09.00\end{array}$ & 1 & & 1 & 1 & & & & 1 & & & & 1 & & & & 5 \\
\hline 4 & $\begin{array}{l}09.00- \\
10.00\end{array}$ & & & & & 2 & & & & & & 1 & & & 1 & & 4 \\
\hline 5 & $\begin{array}{l}15.00- \\
16.00\end{array}$ & 1 & 1 & & 1 & & & 1 & & & 1 & & & & & 1 & 6 \\
\hline 6 & $\begin{array}{l}16.00- \\
17.00\end{array}$ & 3 & 1 & 1 & & 1 & & & & 1 & & & & & & & 7 \\
\hline & Jumlah & 9 & 3 & 4 & 3 & 4 & 2 & 2 & 1 & 2 & 2 & 1 & 2 & 1 & 1 & 1 & 38 \\
\hline
\end{tabular}

Keterangan: Bom (Bombusa, Scolopsis auratus), Tol (Tola), Mam (Maming, Halichoeres dussumieri), Gom (Goropa merah, Plectranthias japonicus), Cip (Ciput), Gos (Gosicina, Parapercis diplospilus), Tat (Tato, Pseudobalistes fuscus), Seb (Ikan sebelah, Asterhombus intermedius), Bok (Boki, Cymolutes praetextatus), Bij (Biiji nangka, Parupeneus heptacanthus), Luk (Luku), Gor (Goropa, Plectropomus oligocanthus), Get (Gete-gete laut, Apogon taeniophorus), Gut (Gutila), Pep (Peperek)

Tabel 2. Sebaran hasil tangkapan (ekor per jenis) dengan umpan tak berekstrak

\begin{tabular}{|c|c|c|c|c|c|c|c|c|c|c|c|c|c|c|c|c|c|}
\hline \multirow{2}{*}{ No } & \multirow{2}{*}{ Trip } & \multicolumn{15}{|c|}{ Jenisi kan } & \multirow[b]{2}{*}{$T$} \\
\hline & & Bom & Tol & Mam & Gom & Cip & Gos & Tat & Seb & Bok & Bij & Luk & Gor & Get & Gut & Pep & \\
\hline 1 & $\begin{array}{l}06.00- \\
07.00\end{array}$ & 2 & 1 & & 1 & & & & 1 & & & & & & & & 5 \\
\hline 2 & $\begin{array}{l}07.00- \\
08.00\end{array}$ & 1 & & 1 & & & 1 & & & & 1 & & & & & & 4 \\
\hline 3 & $\begin{array}{l}08.00- \\
09.00\end{array}$ & 1 & 1 & & & & & & & & & & & 1 & & & 3 \\
\hline 4 & $\begin{array}{l}09.00- \\
10.00\end{array}$ & & & & & & & & & & & 1 & & & & & 1 \\
\hline 5 & $\begin{array}{l}15.00- \\
16.00\end{array}$ & 1 & & 1 & & & 1 & & 1 & & & & & & & & 4 \\
\hline 6 & $\begin{array}{l}16.00- \\
17.00 \\
\end{array}$ & 1 & 1 & & 1 & & & 1 & & 1 & & & & & & & 5 \\
\hline & Jumlah & 6 & 3 & 2 & 2 & - & 2 & 1 & 2 & 1 & 1 & 1 & - & 1 & - & - & 22 \\
\hline
\end{tabular}

Keterangan: Bom (Bombusa, Scolopsis auratus), Tol (Tola), Mam (Maming, Halichoeres dussumieri), Gom (Goropa merah, Plectranthias japonicus), Cip (Ciput), Gos (Gosicina, Parapercis diplospilus), Tat (Tato, Pseudobalistes fuscus), Seb (Ikan sebelah, Asterhombus intermedius), Bok (Boki, Cymolutes praetextatus), Bij (Biiji nangka, Parupeneus heptacanthus), Luk (Luku), Gor (Goropa, Plectropomus oligocanthus), Get (Gete-gete laut, Apogon taeniophorus), Gut (Gutila), Pep (Peperek)

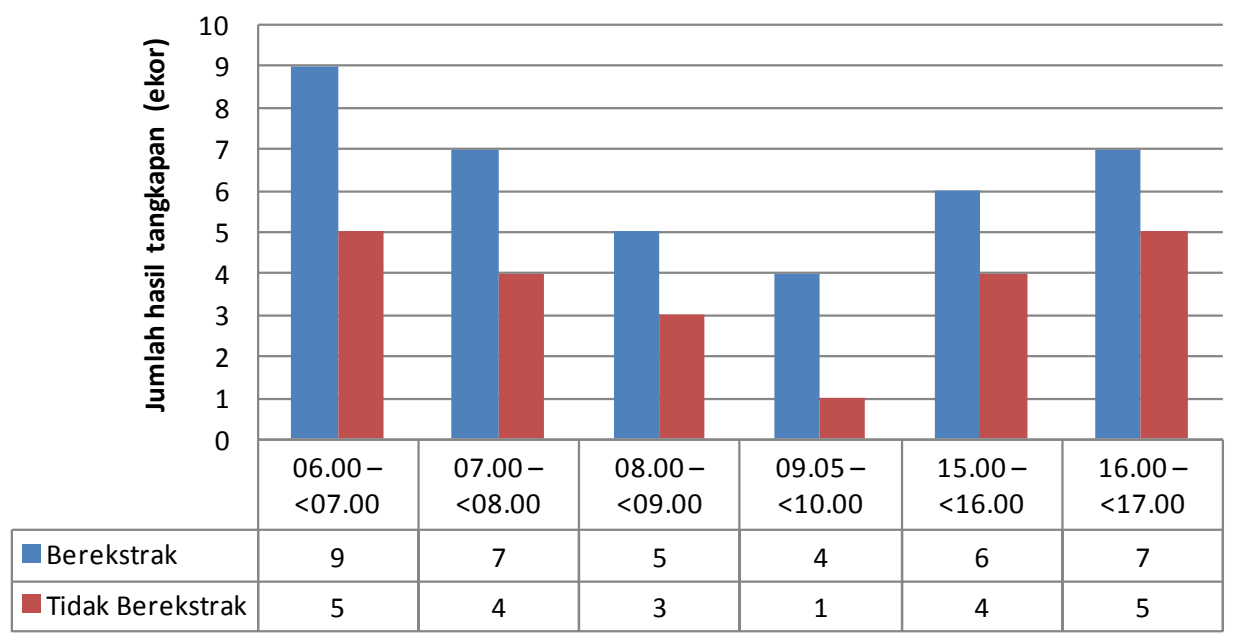

Gambar 1.Tren hasil tangkapan berdasarkan waktu operasi. 
Tabel 3. Sebaran hasil tangkapan pancing dasar berdasarkan jenis umpan

\begin{tabular}{|c|c|c|c|c|c|c|c|c|c|}
\hline \multirow{3}{*}{ No } & \multirow{3}{*}{ Jam Operasi } & \multicolumn{8}{|c|}{$\begin{array}{l}\text { PERLAKUAN UMPAN } \\
\end{array}$} \\
\hline & & \multicolumn{4}{|c|}{ Umpan berekstrak } & \multicolumn{4}{|c|}{ Umpan tanpa ekstrak } \\
\hline & & 1 & 2 & 3 & $T$ & 1 & 2 & 3 & $\boldsymbol{T}$ \\
\hline 1 & $06.00-07.00$ & 4 & 2 & 3 & 9 & 2 & 1 & 2 & 5 \\
\hline 2 & $07.00-08.00$ & 2 & 2 & 3 & 7 & 1 & 1 & 2 & 4 \\
\hline 3 & $08.00-09.00$ & 1 & 2 & 2 & 5 & 2 & 0 & 1 & 3 \\
\hline 4 & $09.00-10.00$ & 2 & 1 & 1 & 4 & 0 & 1 & 0 & $\mathbf{1}$ \\
\hline 5 & $15.00-16.00$ & 1 & 2 & 3 & 6 & 1 & 1 & 2 & 4 \\
\hline \multirow[t]{2}{*}{6} & $16.00-17.00$ & 2 & 3 & 2 & 7 & 2 & 2 & 1 & 5 \\
\hline & Jumlah & 12 & 12 & 14 & 38 & 8 & 6 & 8 & 22 \\
\hline
\end{tabular}

\section{Pembahasan}

Hasil penelitian menunjukkan bahwa penggunaan umpan yang beresktrak lebih banyak memperoleh hasil tangkapan (38 ekor) dibandingkan dengan umpan yang tidak berekstrak (22 ekor). Jika dilihat dari tingkah laku ikan pada saat merespon bau umpan cenderung mendekati kemudian memakannya. Diketahui bahwa umpan yang memiliki ekstrak udang digunakan pada penelitian ini lebih banyak memikat ikan dibandingkan dengan umpan tanpa ektrak. Hal tersebut disebabkan oleh umpan ekstrak memiliki aroma yang lebih tajam dibanding jenis umpan tanpa ekstrak. Umpan ekstrak yang digunakan mengeluarkan bau melalui umpan ikan malalugis yang direndam \pm 1 menit dan terbawa oleh aliran air. Reaksi penciuman ikan disebabkan karena adanya bau yang larut dalam air. Hal ini disebabkan karena kebiasaan makan ikan yakni ikan atau makanan yang baunya hanyut merangsang penciuman ikan sehingga dengan menggunakan umpan ekstrak udang ikan lebih tertarik untuk memakan umpan tersebut, dibandingkan dengan umpan tanpa ekstrak.

Hasil tangkapan umpan yang menggunakan ekstrak udang lebih banyak yaitu 38 ekor dan umpan tidak menggunakan ekstrak yaitu 22 ekor. Ini berarti ada perbedaan hasil tangkapan pada umpan yang menggunakan ekstrak udang dan yang tidak menggunakan ekstrak.

\section{KESIMPULAN}

Penggunaan larutan ekstrak udang pada umpan pancing dasar memberikan perbedaan hasil tangkapan dibandingkan dengan umpan tanpa ekstrak. Jenis-jenisikan hasil tangkapan sebanyak 15 jenis, yang didominasi oleh ikan bombusa 15 ekor (25\%), tola, maming masing-masing sebanyak 6 ekor $(10 \%)$, kemudian diikuti toleh goropa merah sebanyak 5 ekor $(8,33 \%)$, ciput, gosicina masing-masing sebanyak 4 ekor $(6,67 \%)$, tato, ikan sebelah, boki dan biji nangka masing-masing 3 ekor (5\%), luku, goropa dan gete-gete laut masing-masing sebanyak 2 ekor $(3,33 \%)$, dan gutila serta peperek masing-masing 1 ekor $(1,67 \%)$.

\section{DAFTAR PUSTAKA}

Gerry, A., R. Swainston, dan Jill Ruse. 2000. Marine Fishes of Southeast Asia. Periplus.

Lokkeborg, S. 1994. Fish behaviour and longlining. Dalam: A. Fernö dan S. Olsen. Marine Fish Behaviour in Capture and Abundance Estimation. Fishing News Books, Oxford.

Subani, W. dan H.A. Barus. 1988. Alat penangkapan ikan dan udang laut di Indonesia. Penelitian Laut No. 50. Badan Penelitian dan Pengembangan Pertanian, Jakarta.

Soepeno, B. 2002. Statistik Terapan. Penerbit Rineka Cipta, Jakarta.

Sudjana, Nana. 1994. Penelitian Tentang Perikanan Tangkap. Sinar Baru, Bandung. 